
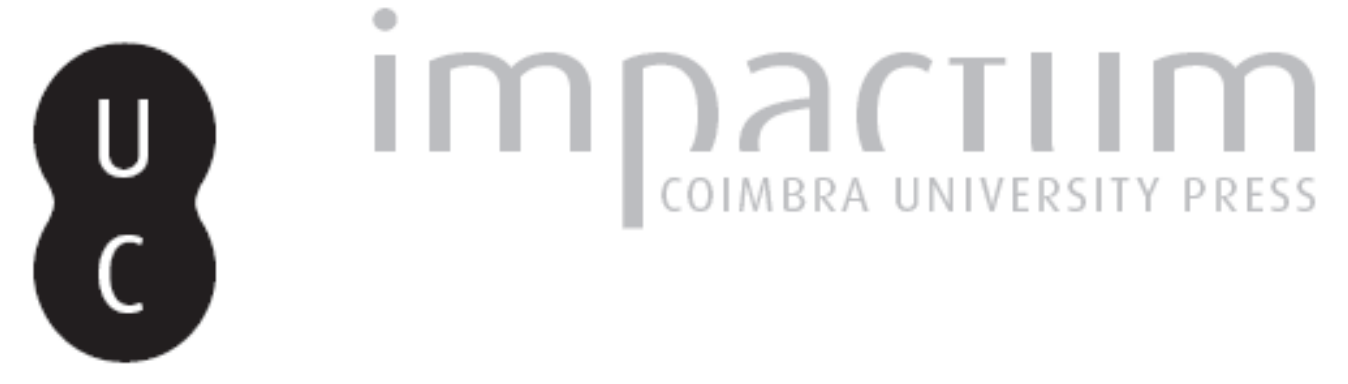

\title{
1848: a primeira crise da teoria económica
}

\section{Autor(es): Bastien, Carlos}

Publicado por: Faculdade de Economia da Universidade de Coimbra

URL persistente:

URI:http://hdl.handle.net/10316.2/25219

DOI:

DOI:http://dx.doi.org/10.14195/2183-203X_34_3

Accessed : $\quad$ 26-Apr-2023 03:20:29

A navegação consulta e descarregamento dos títulos inseridos nas Bibliotecas Digitais UC Digitalis, UC Pombalina e UC Impactum, pressupõem a aceitação plena e sem reservas dos Termos e Condições de Uso destas Bibliotecas Digitais, disponíveis em https://digitalis.uc.pt/pt-pt/termos.

Conforme exposto nos referidos Termos e Condições de Uso, o descarregamento de títulos de acesso restrito requer uma licença válida de autorização devendo o utilizador aceder ao(s) documento(s) a partir de um endereço de IP da instituição detentora da supramencionada licença.

Ao utilizador é apenas permitido o descarregamento para uso pessoal, pelo que o emprego do(s) título(s) descarregado(s) para outro fim, designadamente comercial, carece de autorização do respetivo autor ou editor da obra.

Na medida em que todas as obras da UC Digitalis se encontram protegidas pelo Código do Direito de Autor e Direitos Conexos e demais legislação aplicável, toda a cópia, parcial ou total, deste documento, nos casos em que é legalmente admitida, deverá conter ou fazer-se acompanhar por este aviso.

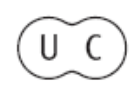


ANA SARGENTO / PEDRO NOGUEIRA RAMOS / GEOFFREY HEWINGS

FILIPE SILVA / CARLOS CARREIRA
INPUT-OUTPUT MODELLING BASED ON TOTAL-USE RECTANGULAR TABLES: IS THIS A BETTER WAY?

FINANCIAL CONSTRAINTS AND EXPORTS: AN ANALYSIS OF PORTUGUESE FIRMS DURING THE EUROPEAN MONETARY INTEGRATION 


\section{8: A Primeira Crise da Teoria Económica*}

\section{Carlos Bastien Gabinete de História Económica e Social do ISEG/UTL}

\section{abstract}

Este artigo tem por objecto o esclarecimento de uma conjuntura particular na história das ideias económicas, especificamente a de 1848. Este foi um ano de crise económica, financeira, política mas também de crise das ideias económicas.

Desta crise resultou o abalar da hegemonia da escola clássica em geral e uma recomposição do campo das ideias económicas, designadamente das de natureza teórica.

Procura-se fundamentalmente esclarecer os contornos e os mecanismos daquela recomposição, designadamente as condições que determinaram a a manutenção da hegemonia da escola clássica e em particular a nova configuração que esta assumiu.

\section{resumo}

This paper aims at clarifying a specific period in the history of the economic ideas: 1848. It was an year of economic, financial, political crisis, which inevitably led also to a crisis in the field of economic ideas.

The classical economy at large, as the mainstream economic school, was questioned leaving ground to a recomposition in the field of the economic ideas, especially concerning its theoretical nature.

The basic features and mechanisms of that recomposition are examined to understand the determinant conditions for the classical school to remain as the mainstream school, even if it took a new configuration.

JEL Classification: B10 
It is the second crisis [of economic theory] in our lifetime - there were others before.'

Joan Robinson

\begin{abstract}
'Aprés 1848, sur une ère où les contraditions de classes son parvenues à complète maturation, celles-ci apparaissent au grand jour lors des combats de Juin à Paris, oú, pour la premiére fois les travailleurs luttent pour leurs propres objectifs. L'issue en est la dissolution complète de l'école ricardienne.'
\end{abstract}

Henryk Grossmann

\title{
1. Introdução
}

A evolução do campo do saber científico económico é marcada por períodos mais ou menos longos de relativa estabilidade, períodos nos quais é clara a hegemonia de um dado sistema teórico e em que há um acumular incremental do saber, mas também por momentos de crise, tendencialmente mais breves, em que essa hegemonia é questionada por sistemas até então dominados ou recém constituídos. De uma conjuntura de crise pode resultar a definição de uma nova hegemonia, e uma rotura no processo de acumulação do saber, como pode resultar a confirmação de uma hegemonia preexistente, ainda que o sistema teórico hegemónico possa nessa situação surgir parcialmente remodelado.

Os demais campos em que se expressam as ideias económicas, o doutrinário, o da política económica e o do senso comum, são condicionados, e eles próprios condicionam, a evolução do campo científico, não obstante manterem uma relativa autonomia em face deste último.

Por outro lado, a evolução, e em particular a emergência e o desfecho das crises da ideias económicas, é condicionada pela evolução da economia e da sociedade em geral e em particular pela relação de forças sociais dentro do próprio campo científico -, pela evolução do contexto intelectual amplo em que tal evolução decorre e pelo desenvolvimento imanente da lógica da teoria económica, não obstante a dificuldade de em cada momento histórico se poder avaliar com rigor o peso relativo de cada um destes factores.

O objectivo do presente paper é descrever um momento de crise da teoria económica, justamente no sentido em que é posta em causa uma dada hegemonia e em que ocorre uma recomposição parcial desse campo do saber - que é um 'espaço de uma luta concorrencial (...) em que está em jogo o monopólio da autoridade científica' (Bourdieu, 1976: 88) -, procurando evidenciar alguns dos mecanismos próprios desse momento. Outras dimensões da crise das ideias teóricas, em particular a sua articulação com eventuais crises de índole doutrinária, político-económica ou do próprio senso comum não são aqui consideradas de forma sistemática. Em momento ulterior será possível aprofundar essas articulações bem como proceder a comparações com outros momentos de crise vividos ao longo dos dois últimos séculos, de modo a esboçar uma teoria das crises das ideias económicas.

A dèmarche que aqui se propõe não é inteiramente inédita. Foram já produzidos estudos sobre diversos momentos de crise das ideias económicas, de que são exemplos marcantes Robinson (1972) e Bell e Kristoll (1981), ou até Thompson (2008) - este com a particularidade rara de se referir ao senso comum -, para além dos múltiplos estudos que incidiram sobre os anos subsequentes à Grande Depressão ou sobre a crise actual. No entanto, nenhum desses estudos tomou por objecto central a crise de 1848, muito embora alguns manuais da especialidade tomem aquele ano como um momento de viragem na história da teoria económica ( $v d$. por todos Vaggi e Groenewegen, 2003). Acresce que nem a generalidade dos estudos sobre a viragem do 
ambiente intelectual na Europa naquele período ( $v d$. por todos Namier, 1992) nem tão pouco a generalidade dos estudos de natureza predominantemente económica e/ou financeira sobre esse momento chave da história europeia referem, pelo menos de forma sistemática, o plano das ideias económicas (vg. Berger e Spoerer, 2001; Dornbusch e Frenkel, 1984; Hyndman, 1932).

Assim, na secção 2 expressam-se os dados fundamentais da crise económica, financeira e política que em 1848 assolou as sociedades europeias e enquadrou a crise das ideias económicas. Na secção 3 fixam-se os traços fundamentais da crise das ideias económicas ocorrida nesse mesmo período e as transformações no campo dos saberes económicos que dela decorreram. Na secção 4 enunciam-se algumas conclusões sobre os mecanismos da crise, mecanismos eventualmente comuns a outras crises dos sistemas teórico-económicos.

\section{A Europa em 1848}

1848 é antes do mais um ano situado no termo da fase B do segundo ciclo de Kondratiev, isto é, no termo de uma fase de aproximadamente três décadas durante a qual as economias nacionais europeias, em particular as mais modernas, conheceram um abrandamento do seu ritmo de crescimento e uma queda continuada do índice geral de preços.

A crise conjuntural que então emergiu foi uma crise geral no sentido em que abrangeu a maioria dos países do continente europeu, particularmente os mais avançados no processo de modernização, e a generalidade dos sectores da vida social, designadamente da económica, sendo que neste último plano se revelou ainda como crise mista, ainda quando atingiu as economias mais desenvolvidas. O grande peso das actividades primárias no conjunto da actividade económica determinou que a sobreprodução industrial e consequente queda dos preços, próprias de uma crise moderna, se articulou com uma crise de subprodução de bens alimentares de origem agrícola e com o consequente aumento dos preços destes produtos, como é próprio de uma economia que não superou ainda completamente o Ancien Régime.

Pelo menos no caso francês, a crise começou por ser uma crise agrícola, resultante de um período de más colheitas em 1845 e nos anos subsequentes, atingindo em seguida as indústrias produtoras de bens de consumo e a nascente indústria de bens de produção, designadamente dos relativos ao sector têxtil. Às restrições ao mercado interno, resultantes da quebra dos rendimentos reais dos agricultores mas também do operariado industrial, juntou-se a quebra das exportações.

A diminuição das reservas metálicas do Banco de França, em resultado do significativo aumento das importações de bens alimentares, e a crescente desconfiança do público transformaram a crise económica em crise financeira. Não obstante o limitado desenvolvimento do sistema bancário, assistiu-se então à redução do crédito, ao aumento das taxas de juro e a um movimento de falências bancárias, o qual atingiu o maior banco privado francês de então, a Caisse du Commerce et de l'Industrie.

Outra dimensão da crise resultou da especulação e posterior colapso do valor dos títulos das companhias ferroviárias após meados de 1846, limitando drasticamente os fundos necessários para a continuação da construção das linhas e paralisando as concessões. Esta crise sectorial acarretou sérias dificuldades para outros sectores importantes da economia, designadamente para a mineração do ferro e do carvão e para a siderurgia.

$\mathrm{Na}$ Inglaterra, à época a economia nacional mais desenvolvida, a crise foi semelhante. Na sua origem esteve também uma quebra na produção agrícola, a que se seguiu a contracção da produção industrial (porventura menos intensa que no caso francês), o colapso da especulação no sector ferroviário e duas importantes crises bancárias consecutivas (também elas acompanhadas da diminuição significativa das reservas metálicas) que, para além de contribuírem para o refrear da especulação bolsista, atingiram as actividades comerciais em geral e a produção industrial, nomeadamente nas zonas Liverpool e Manchester, aquelas em que esta actividade tinha maior expressão ( $v d$. Arnould, 1989: 14-21 em especial, Berger e Spoerer, 2001 e McCartney e Arnold, 2003). 
Estes processos cumulativos determinaram a primeira grande vaga de desemprego na Europa e articularam-se com a emergência de fortes tensões sociais e de movimentos revolucionários na generalidade das sociedades europeias, tanto nas centrais como nas periféricas. A própria Inglaterra conheceu então uma forte agitação cartista sob o lema 'pão ou revolução', mas foi em França que esta dimensão da crise se fez sentir de forma mais marcante, resultando num processo revolucionário violento e na instauração de um novo regime político.

A resposta à crise económica e financeira foi balbuciante, desde logo porque a capacidade regulação estatal naqueles dois países, designadamente para controlar a bolha especulativa no sector das ferrovias, se revelou débil, como débeis se revelaram, uma vez declarada a crise, os mecanismos de intervenção susceptíveis de quebrar os processos cumulativos que haviam conduzido à sua generalização. Na ausência de uma visão teórica do fenómeno em causa, tal regulação assentou em preconceitos doutrinários liberais e em ideias de senso comum, limitando-se a intervenções discricionárias no âmbito da política monetária, em particular na tentativa de fixação das taxas de juro.

Em qualquer caso, dezoito meses após o início da era das revoluções 'todos os regimes que ela derrubara (menos um) tinham sido restabelecidos' (Hobsbawm, 1988: 23). Apenas em França, e num período breve que se seguiu à revolução de Fevereiro, foi possível a instauração de uma 'República rodeada de instituições sociais' (Marx, 1971 [1850]: 57) e com ela o desenhar de um novo tipo de regulação e a definição de uma política económica orientada para o combate ao desemprego, designadamente através da limitação da jornada de trabalho a 10 horas diárias, da criação dos ateliers nationaux e do encorajamento à criação de cooperativas. No entanto, tal modelo de regulação durou pouco tempo. O início de uma nova fase de crescimento económico associado à recuperação política das forças ameaçadas por aquela Segunda República conduziu ao desmantelar do que restava dos mecanismos inerentes àquele modelo de regulação e ao aprofundar dos dados fundamentais do quadro liberal entretanto afastado mas rapidamente retomado pelo Segundo Império a partir de 1852.

As demais sociedades europeias, incluindo aquelas em que as formas sociais pouco foram transformadas pela crise - o espaço alemão foi porventura o mais afectado já que aí adveio a eliminação da servidão - e em que as formas políticas se aproximaram de novo do absolutismo, foram também elas marcadas pela introdução ou reforço de políticas económicas liberais ou liberalizantes. Outras ainda, como Portugal ou a Rússia, em que a crise política não se fez sentir directamente, não deixaram de ser atingidas elos ecos de 1848.

\section{A recomposição do campo do saber teórico}

Este contexto de crise da sociedade burguesa não deixou de afectar a esfera das ideias económicas nos seus múltiplos planos, muito embora o ritmo evolutivo destas não se conforme inteiramente com os ciclos da economia. Nuns casos de uma forma mais directa e imediata (a política económica e o senso comum), nos outros casos de uma forma mais mediata mas igualmente efectiva (a doutrina e a ciência). Centremo-nos por ora na crise da economia enquanto ciência.

\subsection{A hegemonia do sistema teórico clássico}

À data da crise, o campo da ideias económicas, ainda que de limitada dimensão e estruturação, era dominado pelos intérpretes do sistema teórico clássico, o qual havia acompanhado a ascensão do capitalismo. Este sistema tinha-se desenvolvido e hegemonizado o campo dos saberes teóricos a partir de finais do século XVIII com da difusão da Riqueza das Nações de Adam Smith. A partir daí, com as contribuições de David Ricardo e de Jean-Baptiste Say, entre outros, definiu-se uma visão essencialmente estática, polarizada na temática da produção e distribuição do excedente e na ideia que o mercado através do jogo livre da oferta e da procura regula os fluxos de mercadorias e conduz a economia a um ponto de equilíbrio estável. De acordo com a lei dos mercados de Say, dado basilar desta corrente, a procura resulta dos 
rendimentos gerados pela oferta, isto é, na produção, pelo que, independentemente do volume, esta poderá sempre escoar-se sem prejuízo do pleno emprego dos factores de produção, incluindo o trabalho. Neste quadro, o equilíbrio era tomado como o estado natural da economia, de modo que as oscilações económicas não teriam lugar, ou seriam pouco importantes, a não ser em resultado de um eventual choque exógeno (más colheitas, guerras, perturbações financeiras, ...) sempre susceptível de absorção espontânea pela economia.

Os Princípios de economia política de Stuart Mill, originalmente publicados em 1848 , representam o fim do ricardianismo. Encerravam a fase de progresso analítico da economia clássica e assinalavam o início de um período 'de estagnação - um estado que foi universalmente considerado como de maturidade da ciência, se não de decadência' (Schumpeter, 1994: 380). Nos Princípios, Mill alcançava, entre outros progressos analíticos, uma mais clara destrinça entre estática e dinâmica, mas a respeito das crises não revelava uma visão significativamente diversa da dos seus antecessores. A Riqueza das Nações de Smith bem como os Princípios da economia política e de tributação de Ricardo continham já múltiplas referências às más práticas bancárias e Mill, na mesma linha, continuou a atribuir as crises, em particular a da segunda metade dos anos 1840, à especulação financeira e às restrições ao crédito decorrentes da 'retirada do mercado financeiro de parte considerável do capital que costuma supri-lo' (Mill, 1988 [1848]: 183). Em consequência, sugeriu como solução 'a suspensão da lei bancária de 1844' (idem: 184), que conferia o monopólio da emissão monetária ao Banco de Inglaterra e exigia a cobertura integral dessas emissões por reservas de ouro. Na sua visão não havia lugar a outro tipo de intervenção pública já que no fundamental se mantinha apegado à ideia que os mercados, pelo menos os não financeiros, se auto equilibram.

No decurso das décadas que medeiam entre 1776 e 1848, a economia revelava-se uma ciência não unificada, de modo que o sistema teórico clássico surgia então acompanhado e disputado na sua posição hegemónica, por outras correntes teóricas. Em alguns casos por correntes que derivavam do próprio sistema clássico, mas sempre por correntes com menor alcance analítico e diversa expressão social. Sucedeu mesmo que algumas dessas correntes - eventualmente representadas por um reduzido número de autores - enfraqueceram ou dissolveram-se mesmo antes ainda da crise teórica de meados do século. É este o caso de Sismondi, um autor originalmente smithiano mas que, escrevendo ainda antes da primeira crise do capitalismo moderno, aceitou o ponto de vista de que a crescente proletarização e a exploração dos trabalhadores pelos empresários eram regras inelutáveis da economia capitalista e, por outro lado, recusou a ideia de ajustamento automático dos mercados gerado pelo sistema de concorrência, admitindo em seu lugar a existência de uma tendência para a sobreprodução conducente a crises periódicas de gravidade crescente (Novos princípios de economia política, de 1819). Como consequência tornou-se adversário do liberalismo, advogando uma intervenção mitigada do Estado em ordem a limitar as consequências sociais das crises e em particular o desemprego.

Pouco depois, Thomas Malthus (Princípios de economia política, de 1820), que entretanto havia já formulado as suas célebres leis da população e contribuído para a teoria da renda diferencial da terra, retomou a ideia cara a Sismondi de que a economia capitalista tem um tendência inata para o subconsumo, refinando-a embora com a formulação do princípio da procura efectiva e com a afirmação que o crescimento da produção deve fundar-se num crescimento prévio da procura. Na sua óptica, a causa das crises era o excesso de capital e de produtos relativamente aos mercados. A solução adviria assim do aumento do número de improdutivos, do desenvolvimento do comércio interno e externo e de uma política consistente de obras públicas.

O socialismo ricardiano, primacialmente representado por William Thompson (Investigação sobre os princípios da distribuição da riqueza mais própria para gerar a felicidade humana, de 1824) e por Thomas Hodgskin (Defesa do trabalho contra as pretensões do capital, de 1825), foi outro dos sistemas teóricos presentes no campo do saber económico nos anos de 1820 e 1830. A sua problemática central era a da repartição do rendimento e os seus elementos analíticos advinham fundamentalmente da teoria ricardiana do valor-trabalho. No essencial, estes autores consideravam a renda fundiária e o lucro como rendimento confiscado aos operários, muito 
embora em termos política económica propusessem políticas de redistribuição do rendimento e a criação de banco público, mas não transformações revolucionárias em matéria de propriedade dos meios de produção. A excepção era John Bray que sustentava a ideia de transição para uma futura economia colectivizada. Esta corrente teve, aliás, alguma continuidade em autores da chamada 'crítica proletária', designadamente em Constantin Pecqueur, ele próprio um participante activo da revolução de 1848, mas a problemática das crises económicas era-Ihe estranha.

Pela mesma época floresceram inúmeras manifestações de um pensamento económico reformador procurando atalhar os males decorrentes da implantação do capitalismo moderno, males esses particularmente visíveis nos períodos de crise. São disso exemplo as doutrinas económicas moralistas que surgiram 'em defesa daqueles cuja sobrevivência estava ameaçada pelo progresso tecnológico e industrial' (Thompson, 1988: 55) bem como as doutrinas cooperativistas, ligadas ou não ao socialismo utópico. Denunciando ambas as correntes as más condições de vida e as assimetrias de poder inerentes à economia capitalista e propondo arranjos institucionais mais ou menos elaborados quanto à forma de superar tais fenómenos, criticaram a economia política clássica pelos resultados a que as políticas económicas nela inspiradas condiziam, mas não procederam à crítica teórica nem alcançaram dimensão e consistência analíticas susceptíveis de dar corpo a um sistema teórico alternativo.

\subsection{A crise teórica e a sua sequência}

Em qualquer caso, a evidência de uma economia capitalista disfuncional, isto é, com desemprego, associada à emergência da 'questão social' e à crise política nesta segunda metade da década de 1840, precipitou um período de turbulência disciplinar de que resultou o questionar da ortodoxia teórica dominante e a afirmação de concepções divergentes e críticas dessa mesma ortodoxia. Essa afirmação, reflectindo variedade de posições filosóficas, políticas e de interesses sociais, não foi contudo suficientemente poderosa, nem no plano social nem no analítico, para que alguma dessas concepções pudesse tomar o lugar daquela ortodoxia. Foi só já no decurso dos anos 1870 que emergiu uma nova corrente dominante, a neoclássica, implicando uma mudança do foco da análise económica para a problemática do consumidor e a generalização da análise marginal, sem contudo pôr em causa - reforçando até - os dados fundamentais da doutrina liberal.

Até lá, os Princípios de Stuart Mill, mantiveram-se como uma importante referência na divulgação da ciência económica, surgindo quase imediatamente a seu lado, e com forte impacto no Continente europeu, uma renovada apologética do capitalismo concorrencial e do laissez-faire sintetizada desde logo por Frédéric Bastiat (Harmonias económicas, de 1850), que de alguma forma traduzia uma evolução na continuidade do consenso clássico. Foi já então aí visível um enfraquecimento ou abandono de tópicos e conceitos importantes da reflexão teórica, designadamente dos da etapa ricardiana, como o de classe social, a teoria do valor-trabalho e a problemática da distribuição, em favor de uma visão em que todas as interacções humanas se reduziam a actos de troca mercantil fundados na utilidade, muito embora Bastiat nunca demonstrasse com exactidão como é que a utilidade determinava o valor dos serviços produtivos e dos produtos deles resultantes.

Sinal que as crises económicas se mantinham no terreno do 'impensável' é facto de os raros estudos sobre essas mesmas crises terem uma natureza meramente descritiva. $O$ de Clément Juglar, no qual, aliás, a recusa da lei de Say era apenas implícita (Das crises comerciais e do seu retorno periódico em França, em Inglaterra e nos Estados Unidos, de 1862), foi porventura o de maior impacto. Reflexões aprofundadas sobre a natureza das crises financeiras surgiram apenas em meados dos anos 1870 com Walter Bagehot (Lombard Street: a description of the money market, de 1873) e a passagem a estudos de natureza académica não apenas sobre as crises mas mais latamente sobre a mecânica dos ciclos económicos já só ocorreu no findar do século com os trabalhos de Tugan-Baranovsky (The Industrial Crises in England, de 1894).

Entre as correntes divergentes do sistema clássico emergiu o marxismo, 'revelando as roturas operadas entre as classes' (Bernard, 1963: 253) e procurando dar ao movimento operário e ao 
socialismo os elementos de uma análise crítica e sistemática da realidade capitalista. Ganhou dimensão social e teórica a partir da publicação do Manifesto Comunista, justamente em 1848. Afastava-se aí a ideia que as crises eram essencialmente um resultado da especulação e não da sobreprodução, referiam-se 'as crises comerciais que, na sua repetição periódica, e cada vez mais ameaçadoras, põem em causa a existência de toda a sociedade burguesa' e notava-se que 'nas crises declara-se uma epidemia social (...) a epidemia do excesso de produção. A sociedade vê-se de repente transportada para um estádio de momentânea barbárie; (...) a indústria e o comércio parecem-lhe aniquilados' (Marx e Engels, 1975 [1848]: 66). No entanto, o Manifesto era um texto essencialmente doutrinário, com uma dimensão teórico-económica limitada. Nele, bem como no Trabalho Assalariado e Capital, de 1849 - 'o primeiro texto [marxista] propriamente teórico' (Rubel, 1963: 1595) -, e em alguns artigos dos mesmos autores por essa época publicados na Nova Gazeta Renana, surgia uma interpretação da dinâmica secular da acumulação capitalista formulada em termos muito genéricos mas não ainda, como sucederia mais tarde em O Capital, uma teoria desenvolvida do modo de produção capitalista e uma teorização, ainda que inacabada, das crises económicas. Ainda assim, o Manifesto continha algumas medidas com evidente impacto no desenrolar das crises financeiras, desde logo a proposta de 'centralização do crédito nas mãos do Estado por meio de um banco nacional com capital do Estado e monopólio exclusivo' (idem: 85).

Este processo de reconfiguração do campo teórico, que deixou o marxismo à margem dos círculos académicos, envolveu também a emergência da corrente historicista. Esta partia da crítica da ideia, cara aos economistas clássicos, de leis económicas universais para atender privilegiadamente aos processos de evolução das economias, sublinhando a interdependência entre as actividades económicas, as políticas e as culturais e bem assim o papel das instituições no conformar dos comportamentos colectivos, em oposição ao individualismo próprio da metodologia adoptada pela generalidades dos autores da escola clássica. Contrastando com esta escola, os economistas historicistas tomavam a economia nacional como categoria analítica fundamental e procuravam refundar a teoria económica no conhecimento dos factos concretos de modo chegar ao conhecimento das fases e das regras explicativas da evolução das economias nacionais. Esta dèmarche afastava-se também da de Marx já que, ao contrário desta, os representantes da corrente historicista recusavam considerar a validade das leis enunciadas pelos economistas clássicos mesmo quando referidas apenas ao sistema capitalista. Um primeiro momento importante da afirmação desta corrente foi a publicação por Wilhelm Roscher, ainda em 1843, do Compêndio de um curso de economia política segundo o método histórico, mas foi num ensaio posterior (Teoria das crises, de 1849), que se debruçou especificamente sobre a problemática da sobreprodução e das crises económicas, rejeitando a lei de Say e referindo que 'como Lord Lauderdale muito justamente notou, a poupança só é verdadeiramente fecunda na medida em que se desenvolve paralelamente a uma efectiva procura de trabalho ou a uma efectiva procura crescente de bens e de serviços' (cit. Hutchison, 1975: 357).

A situação da crise teórica descrita pode assim representar-se conforme a Figura 1.

Tal como no período anterior à crise, emergiram nesta fase outras abordagens da problemática económica, as quais, no entanto, dado o seu limitado alcance analítico não se constituíram, pelo menos no imediato, em sistema teórico nem trouxeram contribuições para a teoria das crises. Foi o caso, entre outros, do apport de Heinrich Gossen (Desenvolvimento das leis das relações humanas, de 1854), introduzindo o conceito de utilidade marginal, que viria a ter enorme relevância no âmbito do sistema teórico neoclássico.

À margem destas correntes emergiram sobretudo visões doutrinárias, frequentemente desenvolvimentos ou reelaborações de linhas de pensamento já existentes antes de 1848 . Estão neste caso o cooperativismo, o qual, uma vez abandonada a ideia de construção de comunidades humanas sui generis, se converteu numa ideia menos ambiciosa e circunscrita à organização de algumas actividades económicas, e o socialismo cristão, que assentou num conjunto disperso de noções económicas visando a moralização do mercado pela aplicação de princípios éticos em matéria de valor e distribuição. 


\section{4 a}

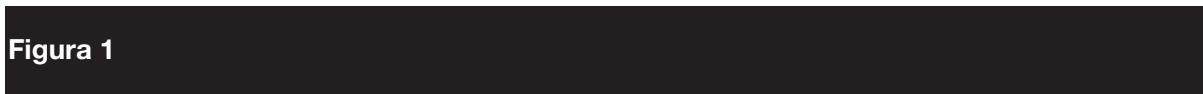

CT

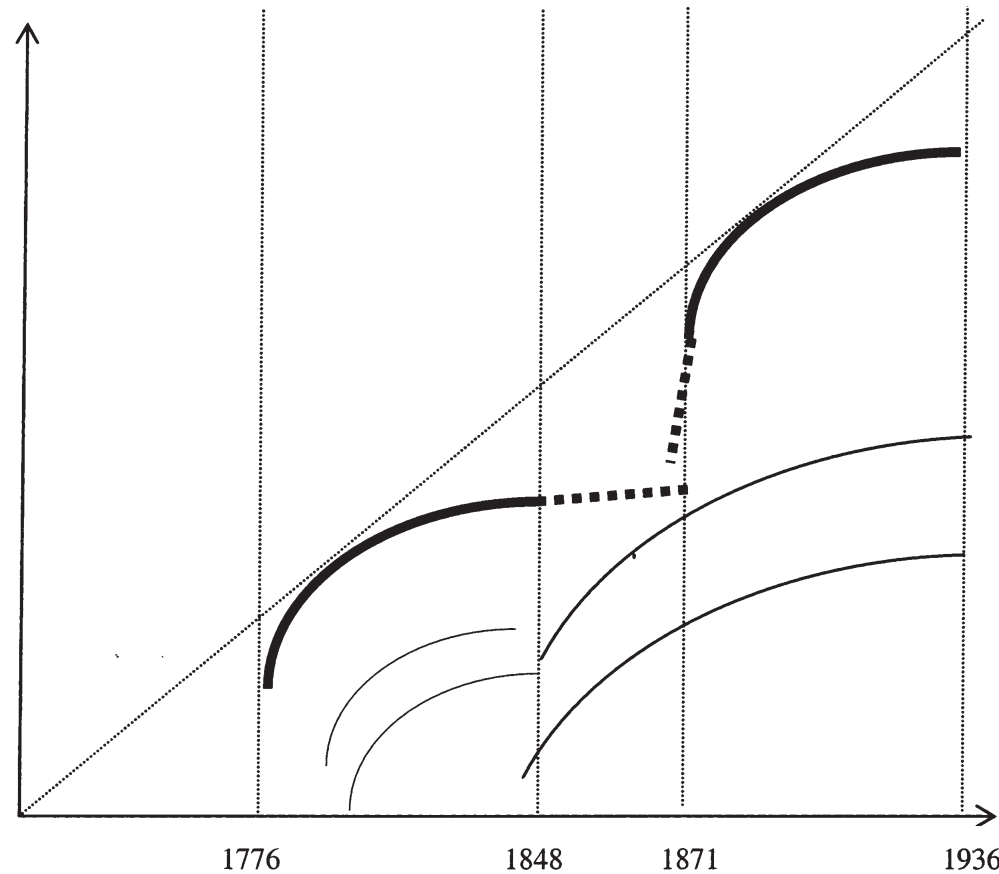

Obs. - CT significa conhecimento teórico.

A bissectriz representa uma curva de possibilidade de produção de saber teórico ao longo da qual se dispõem os diversos sistemas. Significa também que há efectivo progresso - acumulação de saber - ao longo do tempo. Note-se, contudo, que o referido progresso é apenas verificável no interior de um mesmo sistema teórico ou no âmbito da 'evolução e aplicação dos instrumentos analíticos' (Pasinetti, 202: 134), mas não na sucessão de sistemas teóricos (a não ser por uma eventual regra normativa imposta a priori).

As linhas a traço forte representam as correntes maioritárias (e socialmente dominantes) e as linhas a traço fino representam as correntes minoritárias (e socialmente dominadas), o que supõe uma concorrência desigual no campo das ideias económicas. A parte das linhas que surge ponteada indica fase de formação ou decomposição do sistema teórico.

A migração conceitual de uns sistemas para outros não está representada no diagrama.

Também não está representado o sistema de relações microssociais que compõem o campo científico e que constituem o suporte material dos discursos teóricos.

\section{Conclusões}

A crise teórica de 1848 foi breve, como breve foi a crise económica e política que a condicionou, mas nem por isso os seus efeitos foram despiciendos. Ela resultou na reconfiguração do campo do saber económico, e em particular na transformação parcial do sistema clássico, mas não na substituição deste enquanto sistema teórico hegemónico, o que só aconteceu nos anos 1870 mais de duas décadas após o início da crise - com a revolução marginalista. No curto prazo, a solução da crise teórica foi um regresso à hegemonia do sistema clássico, ainda que enfraquecido no seu potencial inovador e parcialmente transformado. Contudo, esse desfecho da crise não era inapelável; outros desfechos da crise política e económica poderiam ter determinado outro desfecho da crise teórica. 
Na circunstância concreta, esta crise revelou que, não obstante aquela transformação e a emergência de sistemas alternativos, o sistema teórico clássico continuou a ser socialmente considerado verdadeiro, já que legitimador das formas de regulação e controlo liberais favoráveis aos interesses históricos dos grupos sociais dominantes. Como justamente observou um historiador do pensamento económico, 'o socialmente perigoso não podia, em hipótese alguma, ser verdadeiro' (Meek, 1971: 97).

É também dado importante desta crise o facto de nenhuma das correntes minoritárias, e socialmente dominadas, se converter no decurso da crise em corrente maioritária, e socialmente dominante, a não ser o historicismo no limitado ao espaço alemão, em resultado da inexistência à data de uma economia e de uma cultura económica globalizadas, do relativo atraso económico daquele espaço e da fraqueza da tradição clássica na cultura económica local. Aliás, este exemplo confirma que o critério de verdade é em última análise um critério de utilidade social.

Os vários sistemas teóricos, e em particular os dominantes, formam-se a partir quer de elementos analíticos originais, quer de elementos teóricos resultantes da decomposição de sistemas anteriores, quer ainda de contribuições téoricas avulsas preexistentes e irrompem na cena do pensamento económico, em articulação com transformações no campo social, enquanto sistemas novos e originais. Por regra - e essa regra aplica-se à crise de 1848 - não há passagem de sistemas dominados a dominantes. 


\section{$6 6 \longdiv { 1 }$}

Referências bibliográficas

Arnould, D. (1989) Analyse des crises economiques d'hier et d'aujourd'hui, Paris, Dunod.

Bell, D.; Kristol. I (1981) The crisis in economic theory, New York, Basic Books.

Berger, H.; Spoerer, M. (2001) Economic crises and the European Revolutions of 1848, iThe Journal of Economic History, 61(2), 292-326.

Bernard, M. (1963) Introduction à une sociologie des doctrines économiques, Paris, Mouton.

Boehm, S. et alii (2002) Is there progress in economics?, Cheltenham, Edward Elgar.

Bourdieu, P. (1976), Le champ scientifique, Actes de la Recherche en Sciences Sociales, 2-3.

Dornbusch, R.; Frenkel , J. (1984) The gold standard and the Bank of England in the crisis of 1847; Bordo, M. e Schwartz, A (eds.)., A retrospective on the classical gold standard, 18211931, Chicago, University of Chicago Press.

Grossmann, H. (1975) Marx, l'economie politique classique et le problème de la dynamique, Paris, Editions Champ Libre.

Hobsbawm, E. (1988) A era do capital 1848-1875, Lisboa, Editorial Presença.

Hutchison, T. (1975) A review of economic doctrines (1870-1929), Westport, Greenwood.

Hyndman, H. (1932) Commercial crises of the nineteenth century, London, George Allen \& Unwin.

Marx, K. (1971) A luta de classes em França 1848-1850, s/l, Nosso Tempo.

Marx, K.; Engels, F. (1975) Manifesto do Partido Comunista, Lisboa, Ediçoes Avante!.

McCartney, S.; A. J. Arnold (2003) The railway mania of 1845-1847 - market irrationality or collusive swindle based on accounting distortions?, Accounting, Auditing \& Accountability Journal, 16(5), 821-852.

Meek, R. (1971) Economia e ideologia - o desenvolvimento do pensamento económico, Rio de Janeiro, Zahar Editores.

Mill, J. S. (1988) Princípios de economia política, vol. 2, São Paulo, Nova Cultural.

Namier, L. (1992) 1848: The revolution of the intellectuals, Oxford, Oxford University Press.

Pasinetti, L. (2002) Progress in economics?, in Boehm, S. et alii (eds.), Is There Progress in Economics?, Cheltenham, Edward Elgar.

Robinson, J. (1972) The second crisis of economic theory, The American Economic Review, 62 (1-2), 1-10.

Rubel, M. (1963) Oeuvres de Karl Marx. Economie I, Paris, Gallimard.

Schumpeter, J. (1994) History of economic analysis, London, Routledge.

Thompson, E., (2008) A economia moral da multidão na Inglaterra do século XVIII, Lisboa, Antigona.

Thompson, N., (1988) The market and its critics, London and New York, Routledge.

Vaggi e Groenewegen, P. (2003) A concise history of economic thought: From mercantilism to monetarism, Houndmills e New York, Palgrave MacMillan. 